\title{
Project of forming «culture and safety» of the airport
}

\author{
Andriy Ivanusa ${ }^{1, *}$ \\ ${ }^{1}$ Lviv State University of Life Safety, Department of Right and Management in the Field of Civil \\ Defence, 79007, Lviv, Ukraine
}

\begin{abstract}
Using the method analysis of the systems and synthesis parameters that influence on the process evacuation of people were certain. Methodological principles are used in relation to the management of people streams on the basis of the use critical path method, where the optimization synthesis of evacuation route people is considered as a topological chart of technological line, and an evacuation way is broken on separate parts. By means of probabilistic method and optimization synthesis of flexible technological lines topological case of users of airport streams frames are worked out and sometimes the evacuation. Conducted analysis of existent mathematical models, that describe motion streams of people on the objects of their mass stay showed that the stream users of the airport mutated and him mathematical description requires the synthesis of a few mathematical models. The method calculation time of evacuation users of the airport in that person informative base drawn on results other undertaken experimental studies is accordingly offered.
\end{abstract}

\section{Introduction}

Realization project construction of object with the mass stay of people envisages implementation complex of measures for providing their safety. Taking into account plenty of people and them psychophysiological properties, unicity planning building, unforecast the state of building, experience from exploitation of building, special approach the projects of safe exploitation of the airports need to providing of safety people. Realization of projects safe exploitation of the airports, in turn, needs realization analysis of normativelylegal base industry of providing safety people, her accordance to the state and world norms and introduction of these norms in practical activity.

Although scientific and technical progress purchased large scales, however the question of safety man in the airports remains actual in future, what tragedies that often arise up on the objects of this type in the process of their exploitation testify to. One of possible directions decision task of increase safety of people in the projects safe exploitation of the airports there are realization and introduction in practice results of scientific researchers from methodology of management projects in the conditions emergencies, and also management and sometimes realization parties concerned of the projects.

\footnotetext{
*Corresponding author: ivaaanusa@gmail.com
} 
Many scientific works have been devoted to the development of new and the improvement of existing methods, models and mechanisms of rescue services management in the system of civil defense of Ukraine. In the works [1-3] the ways of solving the scientifically-applied problem of methodological safe-oriented government construction within development of the difficult organizationally-technical systems projects bases on the example of civil defense are presented. They are offer the system model of safety project of building objects mass stay of people that will realize the methodological going near planning of safety project on the conceptual stage of life cycle. Offered approach to development models life cycle of product, project development infrastructure of the difficult regional system that envisages formalization all basic processes of the system.

Questions of providing safety in different buildings were also raised in many scientific works [4-14]. Particularly, the individual fire risk of death of man from a fire on the objects mass stay of people exceeds a legitimate value that is why there is a necessity for development of additional fire-prevention measures of sent to the increase of level of safe exploitation of object. The analysis of the got the results of the conducted estimation of fire risk is conducted by them showed that the risks of death of man on the objects of mass stay of people largely depended on duration of offensive of maximum-possible values of dangerous factors of fire, that do impossible realization of safe evacuation of people. The use in practice the mechanism of management fire risks offered in their scientific works gives an opportunity considerably to bring down the level of danger for people to the acceptable level during exploitation of objects of mass stay of people.

However, for today there is universal and system approach to realization of projects safe exploitation of the airports, that is characterized by the terms of vagueness, turbulence influence environment, by absence of principles classification in the process of automation selection of information at accepted decisions by top-managers for providing terms of safety and vital functions. Therefore, in future the scientifically-applied task development of new models and methods of management projects remains actual in the conditions of emergencies, namely in industry of management sometimes and by parties concerned of projects safe exploitation of the airports with the aim of providing of safety vital functions of man.

A research aim is development of working tool realization project forming "culture and safety" of the airport. The achievement of the put aim stipulated the necessity decision of such tasks:

1) to conduct the analysis of subject domain, namely projects forming "culture of safety" of the airports, to define their features and descriptions

2) to analyses modern models and methods of management forming "culture of safety" projects, namely in part of management sometimes and management of the airport users in the conditions of origin emergency;

3) to work out models, methods of management users and sometimes in the projects of forming "culture and safety" of the airport.

\section{Material and methods}

In researches approach of the systems is used to the study subject domain of management forming "culture and safety" of the airport, design, topological analysis and synthesis projects for research the existent state of the evacuation system of the airport.

"Culture and safety" - it totality of descriptions and features of activity enterprise, establishment or organization, and also behavior of people that determine priority of risks and development reactions on them. Experience of exploitation of international airports shows that reasons of origin accidents and incidents in any case are related to behavior of people (by a human factor), namely - with their attitude toward the problems of safety. 
As experience shows exploitations of international airports of the world by the most difficult system from higher marked in the plan of the effective functioning there is the system of notification about a fire and management evacuation of people. It is predefined by that other systems for their effective use mainly present technical and organizational to complication on the stage of introduction to exploitation of object, in that time when evacuation of people includes for itself the vagueness of process that requires for her decision complex approach on the stage of domination of object. Thus becomes obvious circumstance that in basis forming of "culture and safety" of the airport there is creation safe terms for realization of timely evacuation of people from building of the airport. It is Therefore expedient in future to consider in detail exactly process of evacuation.

Conducted literary analysis of the advanced studies, methods, methodologies and normatively-legal base [1-18] countries of European Union, that de-scribe motion of streams of people showed that in the architectonically-building planning mathematical expressions are not used for determining size of evacuation ways and exits, but a norm amount of people is used on unit of width of evacuation way. Accordingly, such model describes a human stream as "elementary" streams, parallel rows of people that follow after each other. This model shows: presence of dependence between speed and closeness of human stream and influence on it type of way; necessity to take for basis setting of norms a carrying not capacity, but time of evacuation that depends on totality factors of motion of human stream; pointlessness of setting norms, carrying capacity of way of evacuation is without pointing time of it use. In practice this model is considerably simplified in due with that values of rate movement of elementary human stream after the types way taken on a by minimum: horizontally are a $16 \mathrm{~m} / \mathrm{min}$, stair downward are a $10 \mathrm{~m} / \mathrm{min}$, stair up are a 8 $\mathrm{m} / \mathrm{min}$ the Carrying capacity of elementary stream on a minute also is a permanent size for any type of way: 25 persons/min Width of elementary stream 0,5 - 0,6 M.

One of the simplest there is "Model of motion (without spreading) of human stream of monotonous composition". Exactly this model is used in $[15,16]$. It examines evacuation of people in composition the streams of people and accordingly during realization calculations with the help of this model it is necessary to operate parameters, what characteristic for motion of human stream. Also it shows the amount of people and order of their evacuation, distance and time of evacuation passed by them from the certain area of apartment, place of location stream, value of speed and time spending on reforming of streams. As a result of the conducted calculations on the basis models of this type it is possible to set the geometrical parameters of evacuation ways and exits for providing of unimpeded and timely evacuation of people from apartments.

Therefore in our case it is expedient to take for basis the order of realization of calculations in relation to determination of general time evacuation of people from building of the airport that is driven to $[15,16]$, what operates for today in Ukraine. However, he not in a complete measure describes the dynamics of motion of human stream, that is why during realization of calculations it is necessary to use an additional mathematical vehicle, that is able to describe the processes of spreading, association and reformatting of streams of people.

As a stream of people during motion on building is a characteristic to mutate, then for realization of calculations expediently to break up him on are-as in that there is homogeneity of his motion that will simplify the process of realization of calculations. At determination of time of motion of people, a width and length of every area are accepted in accordance with a project or actual values of parameters of existent building. Length of stair cage or rampant equals length of march, and a path length in the door opening equals a zero. If opening in a wall exceeds 0,7 M., then he must be examined as horizontal evacuation way. Thus, breaking up an evacuation route on areas with the homogeneous stream of people, estimated time of general evacuation of users from building of airport in a 
safe zone will determine after the simplified analytical model of motion of human stream. Taking into account that an evacuation route is broken on some elementary areas, then common time of exit of users of airport will be determined as

$$
t_{\mathrm{ev}}^{\mathrm{zag}}=\frac{l_{1}}{V_{1}}+\frac{l_{2}}{V_{2}}+\ldots \frac{l_{n}}{V_{n}}=\sum\left(\frac{l_{i}}{V_{i}}\right), i=1,2 \ldots n
$$

where: $1_{i}$ - is length of $i$ area of evacuation way; $V_{i}-$ value of rate of movement of users of airport on $\mathrm{i}$ - and to the area of evacuation way, $\mathrm{m} / \mathrm{min}$. In the case when the accumulations of people appear on an evacuation route, then for determination of time of possible delay of motion of people of star will use a mathematical vehicle driven to [15] and it is determined as

$$
t^{\mathrm{szr}}=N_{i} \cdot f\left(\frac{1}{q_{D=0,9} \cdot \delta_{i+1}}-\frac{1}{q_{i} \cdot \delta_{i}}\right)
$$

where: $\mathrm{N}_{\mathrm{i}}$ - an amount of users of airport is on the initial area of evacuation way, persons; $\mathrm{f}$ - area of ichnography of man $\left(0,25 \mathrm{~m}^{2} / \mathrm{m}^{2}\right) ; \delta_{i}$ - width of i- of area of evacuation way, m; $\mathrm{q}_{\mathrm{i}}$ - intensity of motion of streams of users of airport on $\mathrm{i}$ - and to the area of evacuation way, $\mathrm{m} / \mathrm{min}$; $\mathrm{D}_{\mathrm{i}}$ - closeness of motion of users of airport on $\mathrm{i}$ - and to the area of evacuation way, pers. $/ \mathrm{m}^{2}$. Analysing the modified stream of people in building of airport, and, defining his descriptions, it was set that timing of evacuation of users of airport $t_{\mathrm{pr}}$ Erl , is on his separate areas, in a safe zone it is expedient to conduct by means of the use to the model of individually-stream motion of man that is driven to [9], as the modified function of Erlango

$$
t_{\mathrm{pr}}^{\mathrm{Erl}}=\frac{1}{t^{2} \cdot S_{V} \cdot \sqrt{2 \pi}} e^{-\frac{\left(\frac{1}{t_{l p}}-\bar{V}_{p r}\right)^{2}}{2 S_{V}^{2}}}
$$

where: $\mathrm{S}_{\mathrm{v}}$ - dispersion of casual size that is determined after a formula

$$
S_{V}^{2}=S_{V_{0}}^{2}\left(1-\alpha_{i} \ln \frac{D_{i}}{D_{0}}\right)^{2}
$$

$\mathrm{t}_{\mathrm{lp}}$ - time that describes the change of location of man in a stream domain; $\mathrm{V}_{\mathrm{pr}}$ - rate of movement of users of airport for the lobby of airport and it is determined as

$$
\bar{V}_{p r}=\bar{V}_{0 i}^{E}\left(1-\alpha_{i} \ln \frac{D_{i}}{D_{0 i}}\right)
$$

$\mathrm{V}^{\mathrm{E}}{ }_{0 \mathrm{i}}$ - casual size of rate of free movement that depends on the type of way of $\mathrm{j}$ and level of the emotional state of $\mathrm{E}$ of man; $\alpha_{i}$ - it is a coefficient that determines the degree of influence of fluency of users of airport at to motion for i- and to the area of evacuation way; $\mathrm{D}_{0 \mathrm{i}}$ - threshold value of fluency of users of airport, at the achievement of that a closeness grows into a factor that influences on the rate of movement. Value $\mathrm{V}^{\mathrm{E}}{ }_{0 \mathrm{i}}, \alpha_{\mathrm{i}}, \mathrm{D}_{0 \mathrm{i}}$ - wellknown data certain as a result of frequent natural supervisions [9].

Thus, taking into account it is higher marked, common time of evacuation of users of airport in a safe zone will be determined as

$$
t_{\mathrm{ev}}^{\mathrm{zag}}=\sum\left(\frac{l_{i}}{V_{i}}\right)+\frac{1}{t^{2} \cdot S_{V} \cdot \sqrt{2 \pi}} e^{-\frac{\left(\frac{1}{t_{l p}}-\bar{V}_{p r}\right)^{2}}{2 S_{V}^{2}}}
$$


In the case when on the evacuation route of users of airport from certain reasons there will be a delay of motion, then common time of evacuation will be determined in obedience to dependence

$$
t_{\mathrm{ev}}^{\mathrm{zag}}=\sum\left(\frac{l_{i}}{V_{i}}+N_{i} \cdot f\left(\frac{1}{q_{D=0,9} \cdot \delta_{i+1}}-\frac{1}{q_{i} \cdot \delta_{i}}\right)\right)+\frac{1}{t^{2} \cdot S_{V} \cdot \sqrt{2 \pi}} e^{-\frac{\left(\frac{1}{t_{p}}-\bar{V}_{p r}\right)^{2}}{2 S_{V}^{2}}}
$$

To check efficiency of offered mathematical vehicle in practical activity it was expedient to conduct timing of evacuation of users of airport on the real object. Therefore for example a new aerotrain station complex of the International airport was select "Lviv" the name of Danylo Galytskiy (an airport "Lviv"), that was put into an operation in 2012 and needed realization of works in relation to forming of "culture of safety" of airport.

Conducting the analysis of the systems of by volume of plan decisions of air terminal in combination with the specific of functioning of airport on the whole, descriptions of evacuation passage-ways and exits from building. It allowed to create schematic case users frames in the project of forming "cultures and safety" of the airport, that by sight is presented on figures 1 .
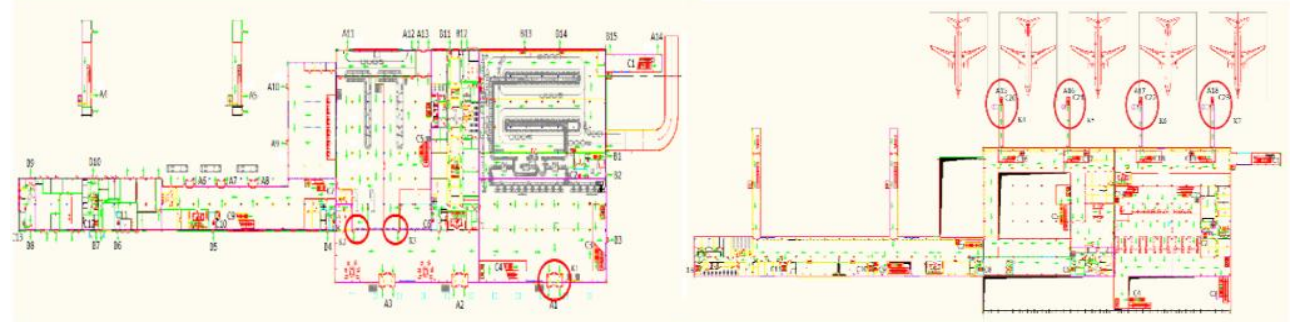

Fig. 1. Schematic model of forming "culture and safety" of the first and second levels aerotrain station complex of the airport "Lviv".

As in basis of project of forming of "culture of safety" of airport there is a management evacuation of his users in a safe zone that belongs to the class of the difficult systems, then the process of evacuation can be examined as a flexible technological line of technological process. Id est the system that depends on the terms of environment is determined by her vital functions and even temper with an environment.

For visual presentation of technological line it is better in all to use a topological design -spatially-geometrical location of totality of elements of the system and integrated connections fixed on a material carrier between them. Such type of design represents the process of evacuation on the whole or on the concrete area of the airport and takes into account his basic constituents. It gives an opportunity to define the critical ways of evacuation users of the airport from the farther-most places of their location and conduct calculations in relation to determination the time of their passing.

Every block of technological line of process of evacuation we will designate as $Z_{i}$, that is characterized by the great number of entry $\mathrm{X}=\left\{\mathrm{x}_{1}, \ldots, \mathrm{x}_{\mathrm{k}}\right\}$ and initial $\mathrm{Y}=\left\{\mathrm{y}_{1}, \ldots, \mathrm{y}_{\mathrm{k}}\right\}$ parameters (ingredients), an operator $F=\left\{f_{1}, \ldots, f_{k}\right\}$, that binds by these data $Y=F(X)$ and sometimes implementations of operation of $t_{\mathrm{i}}$. Great number of $\mathrm{X}$ of entrance ingredients that is included by the block of technological line of process of evacuation (see fig. 2) it is possible to divide into two subsets: $\mathrm{X}_{1}$ and $\mathrm{X}_{2}$. 


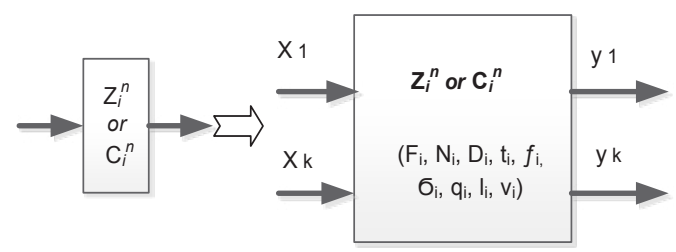

Fig. 2. Visual presentation of block topological case users of the airport streams frame.

The subset of $\mathrm{X}_{1}$ : includes for itself the known weekend such are given as: width $\sigma_{\mathrm{i}}$, length of $l_{i}$ of evacuation way, area of ichnography of man of $f_{i}$, amount of people in the stream of $\mathrm{N}_{\mathrm{i}}$, direction of motion (top, downward, for horizontals) and amount of turns of streams of parties concerned of projects and others like that. To the great number of $\mathrm{X}_{2}$ will take data, that is determined on the separate stage, going out initial data of subset of $\mathrm{X}_{1}$ : closeness, intensity and rate of movement of parties concerned, time of evacuation of previous evacuation way and others like that.

\section{Results}

Using the worked out schematic models of forming "culture and safety" of an aerotrain station complex, probabilistic method and optimization synthesis flexible technological lines of evacuation people, the evacuation ways users of the airport on free territory are presented as a topological model (look at the figures 3, 4).

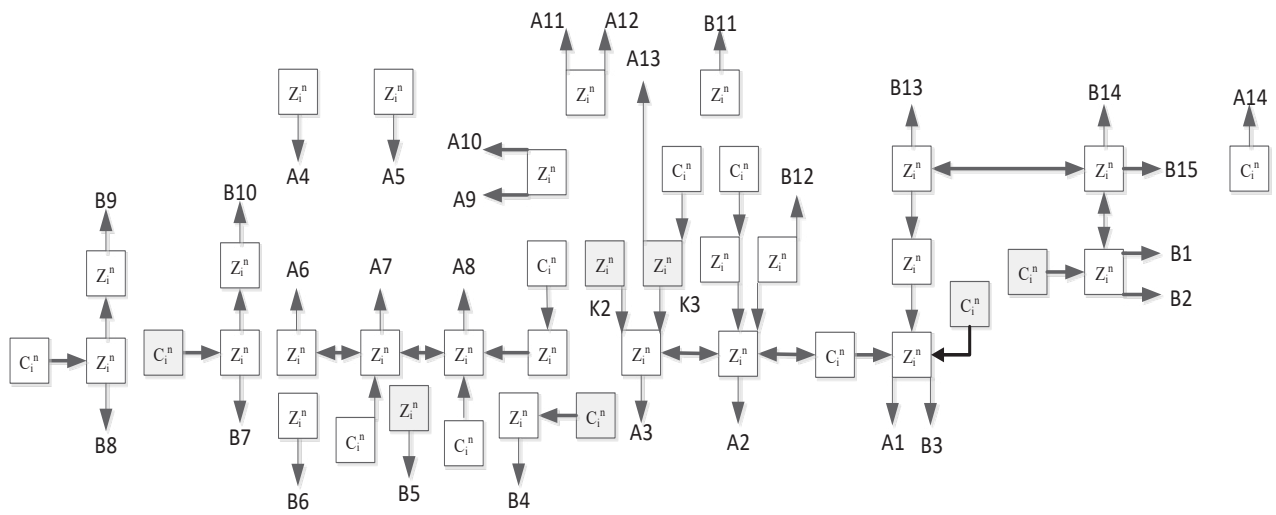

Fig. 3. Topological case users of the airport streams frame at first level.

$\mathrm{Z}_{\mathrm{i}}{ }^{\mathrm{n}}$-is a block of the topological model describing the process of evacuation of people horizontally, on a separate section of the evacuation route, $n=1,2,3,4, i=1,2,3 \ldots j ; C_{i}{ }^{n}-i$ is a block of a topological model that describes the evacuation process of people in stairwells, on a separate section of the evacuation route $n=1,2,3,4, i=1,2,3 \ldots j$. On separate evacuation routes, staircase cells are intermediate evacuation exits from the second, third and fourth floors of the terminal. 


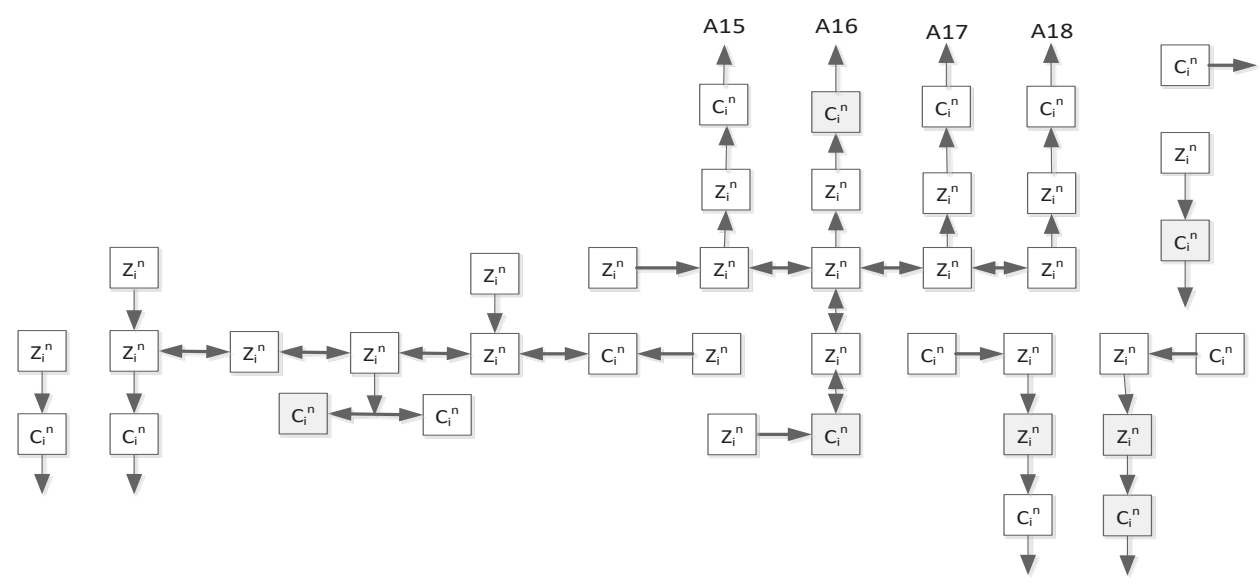

Fig. 4. Topological case of users of the airport streams frame at second level.

Using the worked out topological case of users of airport streams frames, by facilities of spreadsheets timing of evacuation of people was con-ducted from an aerotrain station complex on free territory. The results of calculations are driven to the table. 1. Evacuation of users of the airport, that passed the zone of custom and frontier control and other persons that are after this limit, comes true on territory of air strip.

Table 1. Results of timing of evacuation of people are from apartments aerotrain station complex on territory.

\begin{tabular}{|c|c|c|c|c|c|}
\hline $\begin{array}{c}\text { Apartment } \\
\text { to the terminal }\end{array}$ & $\begin{array}{c}\text { Amount } \\
\text { people } \\
\text { (pr.) }\end{array}$ & $\begin{array}{c}\text { Time } \\
\text { evacuations } \\
\text { (seconds) }\end{array}$ & $\begin{array}{c}\text { Apartment } \\
\text { to the terminal }\end{array}$ & $\begin{array}{c}\text { Amount } \\
\text { people } \\
\text { (pr.) }\end{array}$ & $\begin{array}{c}\text { Time } \\
\text { evacuations } \\
\text { (seconds) }\end{array}$ \\
\hline $\begin{array}{c}\text { Waiting room } \\
\text { № 3 }\end{array}$ & 720 & 247 & Waiting room № 1 & 456 & 232 \\
\hline $\begin{array}{c}\text { Hall of registration of } \\
\text { passengers }\end{array}$ & 300 & 234 & Waiting room № 2 & 370 & 260 \\
\hline $\begin{array}{c}\text { Apartment of treatment } \\
\text { of luggage of passengers } \\
\text { that arrived }\end{array}$ & 200 & 147 & $\begin{array}{c}\text { Hall of treatment of } \\
\text { luggage }\end{array}$ & 12 & 58 \\
\hline $\begin{array}{c}\text { An apartment is for } \\
\text { storage of technical } \\
\text { equipments }\end{array}$ & 4 & 251 & $\begin{array}{c}\text { Apartment of treatment } \\
\text { of luggage of } \\
\text { passengers that arrived }\end{array}$ & 200 & 147 \\
\hline
\end{tabular}

Taking into account the results of the conducted calculations, specific terms of evacuation process, the "narrow locations" are determined on the ways of exit of people from an aerotrain station complex, that it is represented on fig. 1 (red rings) accordingly by the zones of K1-K7. The results of analysis of the obtained data show that by problem places during realization of evacuation of passengers there can be exits of A1, A15, A16, A17, A18 and B8, that is most loaded. Coming from it, in practical activity of the International airport authority "Lviv" named Danylo Galytskiy is given to recommendation in relation to implementation of actions sent to reduction to probability of origin of delay of motion of people in "bottlenecks", and also the evacuation route of motion of users of airport that is represented by green pointers on fig. 1 is worked out. 


\section{Conclusions}

The scientifically-applied task of development of models and methods of forming of "culture of safety" of airport is decided in scientific to work. The basic scientific results of research confirm the achievement of the put aim of work that grounds to do next conclusions:

- the conducted analysis world experience management of safe exploitation of the airports projects set that in basis of project forming "culture and safety" of aerotrain station complexes there is creation of safe terms for realization timely evacuation of people. It is predefined by that on the early stages of development emergency there is the least amount of dangerous factors for life and health of man. Realization of projects of forming of "culture of safety" of airport in accordance with modern requirements provides the safe and comfort terms of stay of people in building.

- the analysis of existent models and methods of forming "culture and safety" of the airport witnessed that the key parameter of safe exploitation of building of airport is time of evacuation of his users in a safe zone, that depends on their amount, geometrical parameters of the evacuation system, competence of personnel and unicity of planning of building.

- on the basis of the use existent by volume of-plan decisions of an aerotrain station complex topological case users frames are worked out in the project of forming culture and safety" of the airport. These models characterize motion of streams of users of airport, carry out a management by them and built on the basis of the use of method of topological analysis and synthesis of flexible technological lines of routing of evacuation ways.

- the method of realization timing evacuation users of an aerotrain station complex of the airport is worked out by the synthesis of mathematical models that describe the evacuation route of users of the airport during the origin of emergency. This method, unlike existing, can provide the search of critical ways and bottlenecks, unload them, execute the redistribution of streams users of project and take into account the change of different types of their motion.

\section{References}

1. O.B. Zachko, D. S. Kobylkin, CSIT 2, (2018)

2. A.I. Ivanusa, Y.P. Rak, EEJAT 1/10 (61), (2013)

3. O. Zachko, R. Golovatyi, A. Yevdokymova, EEJAT 2/3 (86), (2017)

4. N.N. Brushlinskiy, Y. M.Gluhovenko, V. B.Korobko, S. V. Sokolov M.: Bul. Nat. Ac. Sci. Fire Safety 47 (2004)

5. S. Yemelyanenko, Y. Rudyk, A. Ivanusa, CSIT 1 (2018)

6. Y.A. Koshmarov, Academy GPS MVD of Russia, 118 (2000)

7. A.M. Gulida, O.I. Bashinskiy, I.O. Movchan, Fire safety: Collection of scientific works (Lviv: LDU BZD 20, 2012)

8. V.M. Predchenskiy, A.I. Milinskiy, Stroyezdat 375 (1979)

9. V.V. Holshevnikov, D.A. Samoshyn, Academy GPS MCHS of Russia, 212 (2009)

10. D. Shilds, K.I Boys, V.V. Holshchevnikov, D.A. Samoshyn, Fire Exp. Safety 1 (2005)

11. D. Novelli, J. Drury, S. Reicher, Br. Psych. Soc. 49, 2 (2010)

12. A. Sekizava, S. Kakegawa, M. Ebihara, Fire Safety Sci. 9 (2009)

13. L.T. Wong, T.F. Cheung Safety Sci. 44 (2006) 
14. S. Yemelyanenko, A. Ivanusa, H. Klym, CSIT 1 (2017)

15. Order of the Min. of Emerg. Situat. of Russia, (2009, in Rus)

16. GOST 12.1.004-91, Electronic resource: http://document.ua/ssbt.-pozharnajabezopasnost.-obshie-trebovanija-nor3057.html (in Rus)

17. $D B N$ 2.2-9-09, Minregionstroy of Ukraine, 51 (2010, in Ukr.)

18. $D B N$ B.1.1-7, (2002), Electronic resource: http://document.ua/zashita-ot-pozhara.pozharnaja-bezopasnost-obektov-stroitels-nor2817.html (in Ukr.) 